\title{
Designing an Immersive Environment for Public Use
}

\author{
Toni Robertson \\ University of Technology, Sydney \\ PO 123 Broadway, NSW, \\ AUSTRALIA 2007 \\ toni@it.uts.edu.au
}

\author{
Tim Mansfield University of \\ Technology, Sydney PO 123 \\ Broadway, NSW, AUSTRALIA \\ 2007 timbomb@timbomb.net
}

\author{
Lian Loke \\ University of Technology, Sydney \\ PO 123 Broadway, NSW, \\ AUSTRALIA 2007 \\ lian@eng.uts.edu.au
}

\begin{abstract}
Bystander is a multi-user, immersive, interactive environment intended for public display in a museum or art gallery. It is designed to make available heritage collections in novel and culturally responsible ways. We use its development as a case study to examine the role played in that process by a range of tools and techniques from participatory design traditions. We describe how different tools were used within the design process, specifically: the ways in which the potential audience members were both included and represented; the prototypes that have been constructed as a way of envisioning how the final work might be experienced; and how these tools have been brought together in ongoing designing and evaluation. We close the paper with some reflections on the extension of participatory commitments into still-emerging areas of technology design that prioritise the design of spaces for human experience and reflective interaction.
\end{abstract}

\section{Author Keywords}

Design case study, museum displays, interactive art, design processes, multi-disciplinary design teams, scenarios, personas, prototyping, script enactment

\section{ACM Classification Keywords}

H5.m. Information interfaces and presentation (e.g., HCI): Miscellaneous.

\section{INTRODUCTION}

The shift away from the constraints of technology design for traditional work environments is an exciting and often confusing development for those committed to participatory approaches; we find ourselves building very different kinds of technology within very different kinds of design environments to those that initially defined both participatory design tradition and our commitments to it. Yet the boundaries of any discourse are shaped, over time, by what it produces. If participatory design is to remain relevant to novel and emerging technologies then answers to basic questions about participation must be sought within the context in which those technologies are designed, built and used. These include, for example: what participation can mean in practice; what kinds of design practices can be participated in, and in what ways; who should, can and will participate, and when; and who determines the conditions for involvement and decision making.

In this paper we seek to contribute to efforts to extend understandings and practices of participatory design into changed design contexts. We use the development of Bystander, a multi-user, immersive museum environment as a design case study where familiar participative methods and approaches were used in exploratory ways in a novel and complex project. The authors of this paper, as researchers and designers with backgrounds in participatory design approaches and methods, were invited to join an established collaboration of artists to develop and build Bystander. Our motivation was to investigate how the methods, tools and techniques, developed to support participative approaches within traditional computing design environments, might be made both useful and relevant in designing the potential interaction and experiential opportunities within a multi-user, immersive, interactive environment. As users of these kinds of public applications, we had frequently been underwhelmed by our experiences, remembering examples from a range of museum and gallery visits that included broken systems, experiences and content that did not match the rhetoric that surrounded them and environments that were often more disappointing, more confusing, than they were engaging and rewarding. As designers, committed to the participatory design perspective that technology should provide people with the opportunity to influence their own lives (Greenbaum and Madsen, 1993), it seemed to us that 'the public' deserved something better!

It was intended that a careful use of participatory and other human-centred methods, developed and used in more traditional technology design environments, might reduce the risk of a chaotic and otherwise unsatisfactory user experience of Bystander. Exploiting these design methods might foster conditions for more meaningful, reflective and satisfying engagements with both the semantic and aesthetic content of the environment. It was also hoped that 
we might contribute to the process of designing such a complex environment. This included enabling the project team to maximise their focus on designing and developing Bystander itself while minimising the distractions, blockages or diversions imposed by the complexity and non-routine design challenges of the project.

We begin by providing some background to Bystander, describing the system, its various users and the design context. From there we describe how different tools and techniques from participatory approaches were used during the 30-month long process of conceptualisation and design. By presenting this process in some detail, we hope to convey something of the scale and nuances of the design process and the myriad decisions and negotiations, over time, where our participatory commitments were active. We close with some reflections on the role that participatory approaches can play in still-emerging areas of technology design that prioritise the design of public spaces for human experience and reflective interaction.

\section{SOME BACKGROUND}

Bystander is the latest work in Life After Wartime a suite of multimedia artworks created since 1999 by Ross Gibson and Kate Richards, assisted by a production team that has included a graphic designer, a composer and several programmers. In addition to Bystander, the suite consists of four projection screen-based 'interactive' works, a print exhibition, a live performance and a website [14]. All the works in the suite are based on a collection of several thousand photographs, taken by forensic detectives in Sydney, Australia, between 1945 and 1960. These were selected from a much larger archive of crime scene photographs stored at the Justice and Police Museum in Sydney. The photographs show crime scenes from police files. Up to ten photographs from each scene provide a very loose pattern of documentation within the archive; for example, surroundings of the crime, mid-distance, closeups of crime-specific details and so on.

Gibson and Richards have intensively researched and organised the archive over some years, using a range of techniques to recognise existing patterns in the archive and to create new ones that, in Gibson's words, “can add new meanings and moods that have the power of fictions but are historically founded". The photographs are incredibly seductive, hugely evocative images that can easily stand alone as museum and/or gallery artefacts in their own right. They evoke questions in those who view them such as "what happened here?", "who is that person?" and "what have they done?" (see Figures 1 and 2 and [14] for examples). In addition, Gibson has contributed approximately 1500 original short texts to Life After Wartime and there are also thousands of sound files. [1,14].

The objective of this project was to develop an interactive, immersive interface for this collection of images and texts. The longer-term, ongoing aim of the project is to develop a generic, tailorable environment that can be used to display other collections in museum and gallery environments. Bystander is a prototype for how such an exhibition environment might be used and is intended to function as a test-bed that supports a number of future investigations into how different aspects of such spaces are experienced.



Figure 1. Miller St

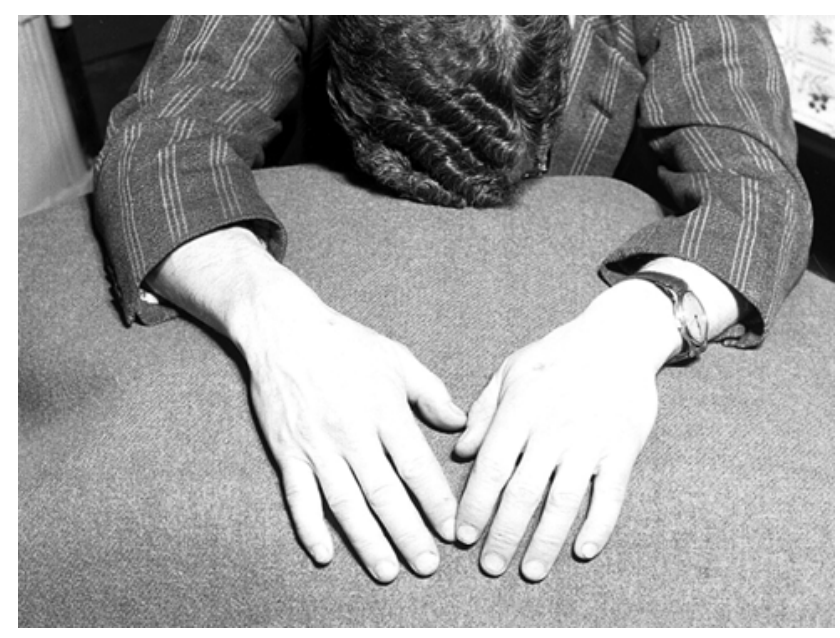

Figure 2. Hands of a strangler

\section{What Is Bystander?}

Bystander is an immersive (in the sense that the audience is surrounded by screens and speakers), multimedia (in the sense that image, visual text, music and aural effects are combined), interactive (in the sense some kinds of movement made by audience members have an effect on the visual and aural display), multi-user (in the sense that multiple actors can interact simultaneously to exert an aggregate effect) artwork designed for display in a gallery or museum space.

Physically, the installation is a pentagon-shaped room of front-projected 4.5 metre by 3.5 metre video screens. Audience members enter through one corner of the pentagon. Sound is delivered by a 5.1 channel sound system. Audience movement is sensed using an infrared 
camera mounted above the top of the screens in the centre of the room and pointed vertically downward. Because Bystander needs to be installed in a range of gallery and museum environments, all computing hardware is of fairly standard commodity specifications.



Figure 3. Flock, images and text

Visitors see a flock of white particles that is present in the room with them in the spaces behind the walls. The activities of the flock are represented by changes in size, density, detail, position, sound and motion that respond to the presence and activity of the room's current and shifting inhabitants. At its broadest behaviour, the flock is disturbed by movement, calmed by stillness. As it moves around, it reveals sets of images and texts dynamically combined in real time (see Figure 3). The relationship between the revealed images and texts is more coherent, more narrative when the flock is calm, less coherent, more associative when the flock is disturbed. In Gibson's words:

The room will behave as if it is hyper-sensitive and 'haunted'...Visitors will learn that they must be composed and attentively still in order to gain the 'trust' of the space, and from there they might be able to develop a 'dance' of intimacy with the images, sounds and texts that surge and retreat in concert with the movement of the people inspecting the space.

As designers we were sceptical about this rhetoric. But if it could ever be possible for visitors to Bystander to experience anything that they might consider "a 'dance' of intimacy" with the room and its contents, then we were committed to using any and every design tool, technique and method we knew to maximise the potential possibility for such visitor participation.

\section{What Does Bystander Do (or not do)?}

Participatory design methodologies have been explicitly introduced to and adopted for museum exhibition design by Taxén [21]. He identified a family resemblance between actively seeking to empower museum visitors to influence the design of the exhibitions and the early Participatory design projects (p. 204). He and others have investigated the design and use of museum displays to encourage particular kinds of user behaviour such as focused learning and audience collaboration (for example, [8,9,10,13,22]). Bystander shares an environment of use, if not of design, with these endeavours, taking advantage of the natural laboratories provided by museums and galleries to investigate both design prototypes as well as the ways in which people discover, explore and create connections [10 p. 157]. In common with other museum design projects, Bystander is both complex and non-routine, employing the skills of a group of people from various communities of practice that bring with them different practices, attitudes and norms [13].

But Bystander differs in many important ways from these other projects. It explicitly and deliberately neither encourages nor supports learning nor any other particular activity. Both artists were very clear about the kind of experience they wanted the room to make available to people who visited it. Gibson described:

... an environment in which something of theirs, which has been wanting or needing to push through can come through, rather than what museums used to think which was "we've got to teach these dummies something".

Bystander is experienced rather than used and offers very little indication of its potential behaviours to those experiencing it. Because it is housed within a museum or gallery environment, those who experience it are free to engage with it or not and are generally also relatively free to define the conditions of any engagement themselves.

Bystander is not intended to explicitly encourage or support cooperative behaviour among its audience. The system has no collaboration facilities as such. But a growing body of research (eg $[8,9,10,22])$ has demonstrated the ways in which people's experiences of public displays is dependent on, and emerges from, their interaction and collaboration with others. The recognition that any user experience of Bystander must, by definition, be social, "constitutively interactive and irremediably situated” [9, p. 227] underlies its development. Emergent cooperation among visitors has always been desired by the project team, even if not always explicitly addressed; it depends on common embodiment inside a space that is made aware of a kind of summation of the presence and activity of all those within it.

\section{Who Are the Users?}

One question we have contended with throughout the design process is: who are the users of Bystander? Or, more appropriately, who needs to participate in its design? We identified four main groups of participants.

The first group is those who might visit the room itself, who would offer what Taxén [21, p. 206] described as expert knowledge of what it means to be a visitor to museums and 
art galleries. Technology design projects, where users are knowable in only the most general sense, have always been especially challenging to those committed to participatory approaches (eg [2,7,17,18,21]). Potential users were both represented, via scenarios and personas developed from user research, and included, as active participants in various prototype cycles and evaluations and, ironically, by the recognition of our own expert knowledge of what it means to visit museums and art galleries. The fact that we did not drive the project freed us, to some extent, to participate as potential (critical) users, (albeit with unusually welldeveloped design skills).

The design and development of Bystander was led by the artists. Yet they relied on collaborators to bring technology design and development skills to the work. We have increasingly come to consider them a second participant group because of their heavy investment in Bystander as a means of continuing their work with the archive of photographs, as well as a means of developing their own oeuvres, reputations and sensitivities to working with digital materials. Building interactive environments such as Bystander is one of the things they do and forms an important basis of their professional reputations. As a consequence, the artists were mainly interested in users who were most like them: those already engaged in some professional capacity in new media and related fields. Our user research found that in smaller art galleries, and museums, that specialised in interactive and/or digital work, the majority of the visitors are, in fact, employed in these fields but visitors to larger museums and galleries are obviously not so specialised.

A third participant group is those who will curate collections and who are charged with making these collections of significant heritage materials available to the public. The project was funded as a research project:

... to stimulate answers to a persistent quandary besetting historians and museological institutions worldwide: how to invent compelling and culturally responsible ways to engage visitors in the interpretive and speculative use of heritage collections so they can grasp more emphatically the vital connections between the past and the present (Gibson, 2003).

Gibson's involvement with the archive is itself an expression of his own curatorial practices, and Richards has also worked with media archives as both artist and producer. But otherwise the interests of this user group will become more active when Bystander is used as a prototype and test-bed for the display of other kinds of collections.

As the development of the work progressed, a fourth participant group demanded a voice. This group was the fragments of past lives represented in the corpus of images itself. The artists wanted Bystander to provide opportunities, perhaps even imperatives, for visitors to bear witness to the events that shaped, even ended, other lives in the not-too-distant past. The power of the images meant they demanded an accountability and commitment, from all of those involved in the project, that would ensure they could fully participate in the shaping of any meanings they may be part of. That is, as much as possible, the images needed to be able to speak for themselves, directly to those visiting Bystander, without inappropriate mediation in the meaning-making process by the technology or the project team. This was perhaps the most challenging participation that the design process needed to enable.

\section{Bystander and the Design Process}

The design and development of Bystander was not a community arts project that might support the kind of ideal user participation more usually sought in classical, participatory design projects [16, 17]. We (we referring, in this paper, to its authors) participated actively in the design process but we did not design, drive or control it. The multimedia development, design and production process, driven mainly by Richards, brought together a team of freelancers including sound designers, programmers, a graphic designer, an exhibition designer, various riggers and some potential users who were reasonably regular visitors to museums and galleries. Some of these people had been involved in earlier works in the suite and returned to make specific, specialist contributions to this one. Besides the artists, we were the only participants involved throughout the design and development of Bystander. Our role was to make available tools to think with for the rest of the project team that could also be used to help the team coordinate its work. Our participation was by invitation and our contributions were generally welcomed, mostly valued and, at times, very influential. But we did not make actual design or process decisions and needed to both justify and adjust our usual design methods, practices, processes and norms [13] to those of the already established and accepted production process.

We do not wish for our participation in a traditional production design process to be read as an indication of our support for this approach in the design of technology such as Bystander. It was not our decision to make, but that of the artists who had, apparently, always worked this way on the development of Life After Wartime. Indeed this production process model is the standard in the working environments where new media works are made. The default within the model appears to be a largely unquestioned assumption that user behaviour is asocial, unsituated, disembodied and designed as much as any other aspect of the production. There appeared to be little understanding, and initially little interest, within the project team, that other, well-established design traditions with well-known and well-tested design methods, processes and expertise existed, and that these might be more appropriate for, or at least be able to contribute to, the design of interactive technology such as Bystander. Our experience would suggest that production design processes will pose particular challenges for advocates and practitioners of participatory design because there appears to be no 
established history for any user involvement, let alone participation, in these processes. Nevertheless, as described in the next section of this paper, the use of participatory methods helped, inspired and supported the members of the project team to build a very complex, non-routine artefact that could not be experienced in situ until its exhibition as a completed work. In Richards' words:

The designers' techniques, brought sophistication and clarity to the development, design and production stages of Bystander. My own creative and production processes have been strongly informed by the experience of working with these techniques (2006).

Finally, Balka and Kahnamoui [2] identified the notion "that the design of technology is only fully completed in use" as being shared by many "who now investigate user participation in design and the domestication of new technologies" (p. 204; see also [4, 20]). Bystander has a particularly interesting family resemblance [21] to those projects shaped by this notion, in that it is the collective visitor participation in Bystander that shapes its behaviour. Despite our other differences, no one in the project team was interested in attempting to 'design the user experience' of Bystander. Instead our efforts went into designing the potentials for visitors to design their own experiences of a heritage collection; the difference is an important one. Bystander is emphatically not a didactic work and every effort was made by all those involved to ensure its meanings were kept open, that those visiting the room could decide for themselves how they participated in it, and that the room could offer its visitors engagement in some kind of shared experience of ongoing disclosure and reflection.

\section{DESIGNING BYSTANDER}

Looking back, it is possible to isolate different points in the design and development of Bystander where the work of designing changed its focus and different phases in the process began and ended. There was, for example, almost a year of design conversations before anything much was actually decided. In that time various aspects of the projected work were researched and the project team developed shared understandings of the emerging design as well as appreciations of some of each other's skills and perspectives. Another phase began when enough decisions had been made about Bystander's behaviour to begin building specific prototypes that could enable different aspects to be explored and that could ground the development of use scenarios. Yet another phase can be traced from the time when prototypes and scenarios could be used together to drive the rest of the design and development process. The various subsections that follow reflect these shifts of focus as a means to bring the different tools and techniques into a narrative for this paper.

\section{Early Stages}

At the very beginning of the project, both artists were interviewed about the previous works in the Life After Wartime suite and their design aims for Bystander. When asked how long people were expected to remain in the room, Richards immediately nominated "six minutes" and Gibson "between 20 seconds and 20 minutes". This short potential time of engagement provided one of the major challenges to the interaction design of Bystander. In addition to looking at the pictures, reading the texts and listening to the sounds that surrounded them, it was required that visitors in the room could also notice that the room was, in some sense, aware of human presence and activities, and was altering the way the images, text and sounds were displayed in response. The challenge was to imagine how, within a short time, amid such richness and complexity, the perceptual systems of actual living people could recognise that a change was not part of the display itself but a response to their own and others' presence and activities. This challenge was further complicated by the somewhat surprising realisation that within the working environments of interactive art making, to which the artists driving the project were accountable, actual technological innovation was often the criteria by which a work was judged and funded, irrespective of how (or even if) it was experienced in practice. We found ourselves acting as the advocates, within the project team, for technological simplicity and restraint in the face of demands for greater and greater levels of technological sophistication, intervention and complexity.

\section{Personas and Scenarios \#1}

Very early on, we developed a number of personas, related use scenarios and a preliminary script of scenarios to represent the expected museum audience and their activities in the room. At this stage no formal user studies had been done and the initial personas and scenarios were developed from interviews with the artists about their impressions of those who visited their own and similar exhibitions in the past. These people were described as "usual museum goers, retired people, school groups, others”. The aim was to provide some use-focused tools to make the potential visitor's possible experience of the room a driver of the design from the very beginning. Their major contribution was in developing a shared understanding of the initial concepts of the project.

But neither the personas, nor the use scenarios, were taken past the first discussion of them at this stage. At the time, we saw this as a failure of the method to translate to this context and assumed this was because we had not based the scenarios and personas on actual user research and so could not ground them. But as in Rönkkö et al.'s study of persona use in the development of consumer software [18] there were other more immediate factors within the design environment that prevented this particular design tool making further contributions at that time. One was that the other members of the project team had no experience of scenarios and how they could be used and resisted the making of any place in the ongoing design process for them. At the time, the artists seemed content with only the most basic abstraction of the potential visitors to the room, 
focusing their interest instead on the design of the behaviour and aesthetics of the room itself. From this perspective it was difficult for us to suggest scenarios as a way to think about user behaviour throughout the process because user behaviour was not yet seen as an issue that needed thinking about. But it was also clear that the personas and scenarios were not sufficiently situated within the experience of the particular kind of technology that was being built [3]. In hindsight they may have been more effective earlier had they focused very specifically on the embodied potentials and constraints that real moving people will always bring to immersive environments such as Bystander.

\section{Looped Mockup}

Some looped footage from an existing work in the Life After Wartime suite was used to provide a simple mockup, on a single wall, to help identify the potential for action and response between those visiting Bystander and the room itself. That footage consisted of a subset of images and texts, of different sizes, moving over a black background. It was displayed on a normal projection screen and some regular museum visitors, unfamiliar with the archive, stood a couple of metres away and watched it. Viewers could not tell if the images and text displayed were in fact the same ones looping round, or if, indeed, they were different. Instead they watched one particular image or text intensively with little awareness of what else was being displayed on the screen at the same time. When that part of the footage looped round again (after only a few minutes), each viewer was looking elsewhere and did not recognise the repetition. Even after numerous repeats of the same footage, using just one screen, viewers did not realise that the footage was looping.

Clearly, from this very simple evaluation, if the presence of one or more visitors in the room was to change the room's behaviour, and if this change was to be perceived, then it had to be very clearly differentiated from the existing, already extensive, changes in display, image size, rate of movement and so on. It was also clear that the possible number of visitor actions, that could initiate a response from the room, were limited. The limits were not imposed by the available technology options to sense and respond to different visitor behaviours; instead they were defined by the power of the images, texts and sounds to fully engage the attention of those experiencing them, leaving little capacity for anything else to be noticed. It was clear that explicit and/or additional interaction with the technology could easily take over as distracting noisy chatter within the total immersive experience that Bystander offered.

\section{Dynamic Mockup}

A second prototype was built to explore a range of technical issues about the display of the archive itself. These included the options for bringing together different images, texts and sounds in real time according to some predefined metadata stored with them, displaying these now-related elements on a screen so they moved across the space in some kind of relation to each other, and gaining a deeper understanding of how such a display would appear to the visitor. The same simple evaluation of standing and watching the display on just one screen was used to evaluate the experience of this prototype. Observers still could not tell if the images were dynamically combined, predefined and/or looping; that is if the system was interactive at all.

But this prototype had different elements moving across the screen space at different speeds, at different sizes and for differing lengths of time. This encouraged attention to the larger, slower moving elements. But it also demonstrated that close physical proximity to a particular wall affected how clearly a particular projected element could be perceived and where and how viewers moved to watch. Size, rate of movement, the time a particular item was visible and the resolution and rate of rerendering of items displayed were identified by participants as variables that needed to be tailorable, preferably in situ, to fine tune the aesthetics and semantics of the room.

\section{User research}

Two separate studies of audience behaviour in immersive spaces were done (see [12] and [15] for fuller accounts of these studies and their findings). The aim of the studies was to provide the project team with a working understanding of potential audience behaviours that could be mapped to whatever behaviour was to be available to the flock of images and texts within Bystander. Participant observation methods were used over several weeks in the main study. The study was set in gallery and museum spaces in Sydney involving several researchers (also frequent museum visitors), who were not part of the project team. A smaller, parallel study of similar spaces in Paris was carried out by this paper's first author. Both studies investigated audience behaviour within available examples of cultural and artistic installations that shared one or more qualities with the aims of Bystander. Traditional museums as well as a range of art gallery environments were visited and revisited in both cities because it was (correctly) assumed that audience behaviour would vary according to the prevailing social protocols of the particular institutions.

Six main audience behaviours, with associated movements, were identified. These ranged from a single glance into an exhibition space from its entrance, to a herd of energetic school children, to the quiet, gentle movements that indicated serious engagement with the work, either alone or in collaboration with others until it was understood. These behaviours were common to each of the spaces studied and to both studies, though the distribution and prevalence of each varied according to specific context. They were also compatible and at times overlapping with the four distinctive phases of new and occasional museum visitors that were identified and described by Falk and Dierking in their seminal work on museum experience [5]. In our case, we were not interested in the progression from phase to 
phase of any individual. Instead our interest was the range of behaviours, and their corresponding movements, that could be present at the same time within Bystander. These provided the range of user input that Bystander needed to be able to respond to in some kind of coherent, predictable and robust way. At the same time a consideration of the effects of different kinds of audience activity provided resources for the designers to consider what those responses might be. The findings from these user studies formed the basis of the personas developed and used in the later stages of development.

\section{Prototyping and User Evaluations}

The insights gained from the early stages of the design provided the basis for the design of Bystander to be more tightly defined and scoped so that programmers, sound, graphic and exhibition designers could become more involved in the project. The growing project team embarked on another iteration of conceptual work about the form that the final work might take.

\section{Exploratory Single-Screen Prototype}

The artists settled on a concept of Bystander based on the idea that the images and text might move similarly to a flock of finches, using an algorithm simulating flock movement. As the room became more agitated in response to the movements of the audience, this flock would become more nervous, splitting and moving more erratically. An exploratory prototype using the flocking algorithm was developed. This prototype moved through several distinct iterations; each was demonstrated for the entire team.

Most importantly, this prototype provided a user interface that exposed the algorithm's parameters to user control. These included those, such as size, rate of movement and rendering, that had been identified as noticeable by participants in the dynamic mockup evaluation. The aims were to provide the artists with direct control of the algorithm and to address the identified need for tailorability of the whole system.

This user control was also designed to help overcome difficulties in communicating artistic intent to the rest of the team. The artists were encouraged to develop and save proposed behaviours of the media flock directly. The programmer could then plot mappings between the narrative logic of the system, those flock behaviours and the transitions between the different states of the system. The exploratory prototype continued to function, throughout multiple iterations over the life of the project, as a medium of communication between the artists, the graphic designer, the programmer and us. It superseded the more familiar practice of crafting written briefs describing the desired behaviours, that were tedious and difficult for the artists to write and difficult for the developers to interpret satisfactorily. Both the developers and the artists reported that using the prototype for communication in this way was experienced as more direct and less error-prone.

\section{Distributed Rendering Prototype}

As the artists became clearer about how they wanted the system to behave, the prototype was developed beyond the single screen version into a distributed system running on several computers and displaying on five screens. When viewed on several screens, at closer to its full size, the flock was more satisfying with many more members (1000s compared to the 20 or 30 in earlier, single screen versions). In a significant conceptual shift, the flock was reimplemented using a single graphic for each particle instead of a scanned photograph. As the flock moves around the space, it reveals ensembles of photographic images and text fragments. These appear to detach from the flock, in a brief, animated transition, hang briefly in space and then fade.

This prototype exposed other issues related to scale and geometry. For example, as the media flock moved around the five screens, audience members were at risk of vertigo. Ironically, the flock moves in a rhythmic, circular pattern when it is calmest and most inclined to divulge the hidden narrative; this is the state most likely to cause physical discomfort to visitors. So in the calmer modes, when more reflective viewing was encouraged, two or three screens are the maximum on which the flock reveals images and texts.

A sound synthesis system was developed in parallel to the visual prototype to expand and reinforce the visual concept. The system combines an ambient soundtrack (to connote the mood of the room), flock sound effects and composed sound stings (to both drive and reinforce the interactions between the flock and the audience). Places for the sound and the visual systems to link became more evident as the developing Bystander was experienced closer to full-size.

\section{Personas and Scenarios \#2}

A series of personas was developed from the user studies to represent the range of visitors to the spaces considered. These were compared to, eventually combined with, those developed early in the project from interviews with the artists. We were encouraged by the remarkable similarities in the two sets of personas despite those people developing the personas from user research not being aware that the original set existed. In previous projects we had deliberately tried to keep the numbers of personas to a minimum to allow for a number of scenarios to be written for each. In this case though we needed to develop multiple examples of basic personas to populate the Bystander prototype over time so that different combinations and effects could be investigated. A range of individual characters was created for each persona. Note that these characters were not a return to individual users but were designed to carry the characteristics of the personas through time and multiple instances within the testing environment.

\section{Producing the user interaction script}

Scenarios of each character's movement and activity inside Bystander were developed then joined together in a script that could structure the exploration and evaluations of various models and prototypes of Bystander over time. The 
script, too, built on the earlier version by further developing and simulating various scenarios of audience activity that were grounded by the observations made during the user studies. Care was taken to ensure that the full range of audience behaviours we had observed was captured in the script, as well as a wide range of different configurations of people in the room.

The script was structured to match audience and system behaviour and sensibilities. This allowed the mapping of action and response, where appropriate, from both the user and the system perspectives, as well as making the perceptual disparity between the two available. This approach was inspired by the analytic framework Suchman used to identify available conversational resources in her classic study of photocopy use [19]. Audience behaviour was described in terms of motion, presence and stillness. Both the position of individual audience members and spatial configurations of multiple visitors were treated as significant inputs to the system.

An augmented set of Labanotation designed for group choreography [11] was used to describe a set of movement schemas. These were developed to illustrate the changing spatial configurations and trajectories of the users in the script of scenarios. They provided an easily learnt, at-aglance view of the overall activity in the room in terms of the path, position, orientation and movement of multiple users in space and time. By matching these schemas to the script it was possible to map the movements of individual characters both within Bystander and in relation to other characters participating in the experience with them. See [12] and [15] for detailed discussion of the scenarios, scripts and movement schema and their use.

\section{PUTTING IT ALL TOGETHER}

Continuous prototyping and user testing could not be carried out with a full-scale system because it was not possible to have a permanent testing room set up during development. But we were able to establish a temporary, full-scale, pentagon-shaped, testing room on two occasions, about two months apart. A morning session was set aside for user testing on both occasions. Each iteration of user testing focused on those aspects of participation that were possible in the current form of the prototype environment. The user interaction script was used to drive each session; it was refined each time to suit the current requirements. During both testing sessions, members of the project team together with participants, who were potential users, acted out the different characters in the script. All were provided with the user interaction script and the set of linked movement schemas that described a sequence of scenarios over a 40 minute period. Different characters were allotted to each participant during that time and they were briefed on the purpose of the script, their roles in playing out the script and how to follow the movement schemas. During actual enactment, the participants were directed through the script. At the end of each enactment the potential users were debriefed and their responses fed back to the project team so that appropriate changes could be made to the still developing behaviour of the room both during the testing days and in the following weeks.

The enactment of different characters helped both members of the project team and the user participants to elicit a range of different experiences of Bystander. The influence of other people's presence and activity in the room on an individual audience member's experience and perception of the work was made evident [22]. It was clear that the presence of several other people would be necessary for any individual to experience all aspects of the work [10]. This meant that the project team needed to think in terms of a range of satisfying potential experiences for various configurations of people in the room.

The interaction script and its accompanying movement schemas were intended to enable the project team and a range of potential users to experience together aspects of the work that had not been possible until they could immerse themselves over time in a full-sized prototype of the room. Until this point, much of the design conversation about the interaction between different members of the audience and between the audience and the room had been speculative and ungrounded. One of the most interesting results of the first scenario enactment session is that during all further testing all members of the project team, who were not actually driving the session, moved into the testing room itself. Prior to the enactment, some members of the team had sat with those driving the tests or in some other position outside the room looking in. After the enactment, it was assumed that Bystander was best experienced directly rather than observed from the outside.

The experience of immersion in the working prototype and the responses and feedback from potential visitors resulted in a refinement of the project team's understandings of the specific interactive nature of Bystander. A number of issues regarding the design could be more fully explored and understood. For example, the user studies had found that activity around the entrance to the space needed to be addressed separately to the rest of the space. This was because some gallery-goers could just peek in or enter only briefly and then leave again. There were design questions that needed to be asked about what actually counted as presence in the space itself. The working assumptions had always allowed for sensors to be placed at the entrance but these were dropped completely after the first scenario enactment on the basis that entry clearly did not equate with presence and presence would be more appropriately sensed by other, still to be decided, means.

The first enactment had as its second aim the development of some sense of audience stress testing that those building the system could use to ensure the system did not break down if too many people and/or too few people and/or too much movement and/or too little movement was in the room at any particular time. Later versions of the user 
interaction script were developed to support the project team's understandings of other aspects of the design such as audience movements in response to different experiences of the aesthetic content of the room.

This stage completed our formal participation in this part of project. The nature of Bystander is that it can only be available for full user evaluation during those times when it is actually installed in a public museum. This evaluation will then inform the development of a generic version of the technology that can be used to display other kinds of heritage collections.

\section{DISCUSSION}

In 1993, Joan Greenbaum and Kim Madsen wrote a small, personal statement identifying three different perspectives for the need for participatory design approaches in technology design-the pragmatic, theoretical and political [6]. These, they contended, were adaptable cross-culturally to extend the discussion of participatory approaches outside of their roots within Scandinavian experiences in traditional work environments. Robertson (1998), for example, exploited these perspectives to consider how participatory design approaches might be relevant to small design companies. We revisit them here as a tool to structure this discussion of the process of bringing participative practices to the design of Bystander.

In the first instance, our exploration and exploitation of various tools and techniques from participatory design perspectives was pragmatic-our motivation was "getting the job done better" [6]. On the one hand, we sought to make tools to think with available to the project team, to enable them to focus as directly as possible on the design by assisting in the general management of the various stages of the design process. On the other hand, we sought to use design tools that would ensure that the experience of those visiting the exhibition would be central to the design process and that design decisions were always accountable, in a range of ways, to that experience. In practice, the design tools we used offered the various participants ways to test, reflect and refocus their decisions throughout the design process that were always grounded in a concern for those who will experience Bystander in use. For us, being able to call on our repertoire of these same tools provided a way: to approach the design of a non-routine system; to orient ourselves to unfamiliar development processes and criteria; to negotiate our presence within, and contributions to, a multidisciplinary and novel development team; and most importantly, to contribute to new ways of technology being built that we hoped would extend the motivations and priorities of participatory approaches into emerging technology design fields and practices.

Greenbaum and Madsen suggested that one strength of their theoretical perspective was its focus on building shared understandings between different stakeholders in the design process. Despite the differences in time, place and technology, this was perhaps the major contribution of the design tools we could bring to Bystander. This was a very multidisciplinary group; confusions of language, divergent understandings of the project, the concept, the technology, team roles and so on have repeatedly arisen and been resolved. The iterative development of the mockups and the exploratory and full-scale prototype and our enactment of scenarios within it, played a core role in the creation and maintenance of shared understandings of Bystander.

Bystander has provided us with a fascinating new context in which to apply not only these pragmatic and theoretical perspectives, but also their companion political perspective. Greenbaum and Madsen argued that as systems developers we have the responsibility to provide people with the opportunity to influence their own lives. Clearly the political perspective of participatory design has moved beyond the workplace along with the technology we build and the design and disciplinary traditions we work from. For all of us who contributed to the design and development of Bystander, irrespective of our particular disciplinary commitments and backgrounds, technology was always seen as being of service to the agency of the extraordinary collection of images and texts, those whose lives are represented to us in the photographs, and the activities and meanings that could emerge from people's engagement with them and with each other.

The project raised interesting questions about the location and distribution of power in the social circumstances surrounding its development. We were concerned to maintain the power of the artists to express a certain vision of the work, but equally to ensure the power of the audience to create their own experience of it. We became advocates for future curators investigating other heritage collections of images. Finally, the entire team accepted a responsibility towards the archive and the fragments of lives it represents. As designers, we gained some valuable, sobering insights into the experience of participation in a design process without the accompanying power to make decisions.

From the perspective of our involvement in Bystander, Greenbaum and Madsen's framework is still a useful way of reflecting on participatory approaches to the design of new environments. While we seem to have moved a long way from so many of the immediate concerns of early participatory design, its tools and techniques have transformed, translated and migrated to new environments in remarkably effective ways. At the beginning of this paper we stated that if participatory design is to remain relevant to novel and emerging technologies then answers to basic questions about participation need to be sought within the context in which those technologies are designed, built and used. In the development of Bystander we used a range of tools from participative approaches including field studies, personas and scenarios, rapid and iterative prototyping as well as constant and ongoing attention to understanding who could and needed to participate in the process and how that could be enabled. Along the way these tools were 
extended and shaped to be effective within the context of Bystander's development.

But this has not been a trivial, routine application of either a recipe of design rules and practices or even good engineering. In the same way that, in the first instance, participatory design demanded a situated, radical, creative approach to the application of design techniques to particular work places, the application of the standard toolkit of participatory approaches to new contexts of use still required of us, and probably always will, the same situated, radical creativity. By providing this detailed study of the design of Bystander we hoped to contribute to participatory design some sense of the degree of engagement in the minutiae of design decisions and process that was required to move into this particular instance of novel technology design. For us, the key was not just the adherence to particular design tools and techniques but the commitment to Greenbaum and Madsen's political perspective. It was this commitment that motivated us to continually seek out ways of designing Bystander to prioritise its accountability to the range of people who are eventually going to experience it and to improve the quality of experiences available to participants in an immersive environment designed for public use.

\section{ACKNOWLEDGMENTS}

Bystander is funded through the Australian Research Council Linkage Program. We thank Ross Gibson and Kate Richards for the opportunity to contribute to this project, Daniel Heckenberg and Greg Turner for their invaluable assistance in prototype development, Greg White, Jon Drummond, Tim Gruchy and Aaron Seymour for their work on the final implementation and Melanie Kan, Lizzie Muller and Kirsten Sadler for their user research.

\section{REFERENCES}

1. Australia Council, Arts in Australia: Gibson http://www.ozco.gov.au/arts_in_australia/artists/artists_ new_media_arts/Gibson, 2003.

2. Balka, E. and Kahnamoui, N. Technology trouble? talk to us: findings from an ethnographic field study, Proc. PDC 2004, CPSR, (2004), 224 - 234.

3. Bødker, S. Scenarios in user-centred design - setting the stage for reflection and action, Interacting with Computers 13, 1 (2000), 61-75.

4. Clement, A. Computing at Work: Empowering action by 'low-level' users. Comms of the ACM 37, ACM Press, (1994), 53-63.

5. Falk, J and Dierking, L. The Museum Experience, , Whalesback Books, 1998.

6. Greenbaum, J. and Madsen, K. H., PD: A Personal Statement. Comms of the ACM 36, 6, ACM Press, (1993), 47.
7. Grudin, J. and Pruitt, J. Personas, Participatory design and Product Development: An Infrastructure of Engagement. Proc. PDC2002, CPSR (2002), 144-161.

8. Heath, C., Luff, P., vom Lehn, D., Hindmarsh, J. and Cleverly, J. Crafting participation: designing ecologies, configuring experience. Visual Communication 1, 1 (2002), 9-34.

9. Hemmings, T., Randall, D., Marr, L., and Francis, D. Task, Talk and Closure. Situated learning and the use of an 'interactive' museum artefact. In Hester and Francis, Eds. Local Educational Order. Ethnomethodological Studies of Knowledge in Action, 2000.

10. Hindmarsh, J., Heath, C., vom Lehn, D. and Cleverly, J. Creating Assemblies in Public Environments: Social Interaction, Interactive Exhibits and CSCW. Computer Supported Cooperative Work 14 (2005), 1-41.

11. Hutchinson, A. Labanotation or Kinetography Laban: The System of Analyzing and Recording Movement. 1977.

12. Loke L. and Robertson, T., Moving Bodies, Social Selves: Movement-Oriented Personas and Scenarios, Proceedings of OZCHI2005.

13. Lee, C., Between Chaos and Routine: Boundary negotiating artefacts in collaboration, Proc. ECSCW 2005, (2005) 387-406.

14.Life After Wartime. Project website http://www.lifeafterwartime.com/

15. Robertson, T., Loke L., Kan M., Muller L. and Sadler K., Personas for Interactive Exhibits in Public Museums, IDWOP Technical Report, (2005) http://research.it.uts.edu.au/idwop/publications3.html.

16. Robertson, T., Early Community Arts in Australia. In Art Network, 5, (1982), 18-20.

17. Robertson, T., Shoppers and Tailors: Participative Practices in Small Australian Design Companies. Computer Supported Cooperative Work 7 (1998) 205221.

18. Rönkkö, K., Hellman, M., Kilander, B. and Dittrich, Y. Personas is not applicable: local remedies interpreted in a wider context. Proc. PDC 2004, 112-120.

19. Suchman, L., Plans and Situated Actions, Cambridge University Press, 1987.

20. Suchman, L., (1994) Working Relations of Technology Production and Use. Computer-Supported Cooperative Work, 2 (1994), 21-39.

21.Taxén, G. Introducing participatory design in museums, Proc. PDC 2004, (2004), $204-213$.

22. vom Lehn, D., Heath, C. and Hindmarsh, J. Exhibiting Interaction: Conduct and Collaboration in Museums and Galleries. Symbolic Interaction 24 (2001), 189-216 